\title{
SYAIR MASYARAKAT TORAJA: PERTAUTAN ANTARA KEARIFAN LOKAL DENGAN PENDIDIKAN ISLAM
}

\author{
Arhanuddin Salim \\ IAIN Manado, Sulawesi Utara \\ Yunus Salik \\ Universitas Pamulang, Jakarta \\ Ismail Suardi Wekke \\ Sekolah Tinggi Agama Islam Negeri Sorong, Papua Barat
}

\begin{abstract}
ABSTRAK
Studi ini bertujuan untuk mengetahui relevansi nilai-nilai budaya dan pendidikan Islam. Himne Pasomba Tedong merupakan upacara syukuran tertinggi dalam kehidupan orang Toraja, yaitu pada upacara maqbuaq dan meruaq yang diperuntukkan kepada Puang Matua(Tuhan), yang bertujuan untuk memohon kesuburan tanah dan memudahkan interaksi sosial masyarakat dengan mengorbankan seekor kerbau muda hitam dan gemuk. Ungkapan-ungkapan tersebut mengandung nilai-nilai pendidikan nilai religi, nilai persatuan, nilai musyawarah mufakat, nilai etis, dan nilai tenggang rasa/saling menghormati yang memiliki relevansi dengan Pendidikan Islam dan diharapkan agar bahasa dan ungkapan-ungkapan masyarakat toraja dimasukkan dalam mata pelajaran muatan lokal pada semua jenjang pendidikan di sekolah demi memelihara kelestariannya dari kepunahan sebagai aset budaya bangsa. Kemudian diinternalisasikan melalui pendidikan informal dalam lingkungan rumah tangga serta di sosialisasikan dalam masyarakat melalui senibudaya sebagai bagian dari pendidikan non formal.
\end{abstract}

Kata Kunci: Nilai-Nilai Kearifan Lokal, Syair Toraja, Relevansi, Pendidikan Islam

\begin{abstract}
This study aims to determine the relevance of cultural values and Islamic education. Hymn Pasomba highest Tedong a thanks giving ceremony in the life of the Toraja, namely at the ceremony maqbuaq and meruaq intended to Puang Matua, which aims to invoke the fertility of the soil and facilitate social interaction with young buffalo sacrificed a black and plump. Those phrases containing educational values religious values, the unity, the value of consensus, ethical values, and the value of tolerance/respect that have relevance to Islamic education and hoped that the language and expressions of Toraja society included in the content subjects local at all levels of education in the school to preserve the continuity of extinction as the nation's cultural assets.
\end{abstract}


Keywords: Values Local Wisdom, Poetry Toraja, Relevance, Islamic Education

\section{I . PENDAHULUAN}

Suku tana toraja adalah suku yang menetap di pegunungan bagian utara Sulawesi Selatan, Indonesia. Populasinya diperkirakan sekitar 650.000 jiwa, dengan 450.000 ribu diantaranya masih tinggal di kabupaten Tana Toraja. Mayoritas suku Toraja memeluk agama kristen, sementara sebagian menganut agama islam dan kepercayaan animisme yang dikenal sebagai Aluk Todolo. ${ }^{1}$

Suku Toraja salah satu suku yang kaya dengan sastra daerah yang diungkap adalah nilai-nilai budaya dalam sastra Toraja, khususnya himne Pasomba Tedong. Himne Pasomba Tedong adalah pengiring upacara yang diucapkan pada upacara syukuran tertinggi dalamkehidupan orang Toraja, yaitu pada upacara maqbuaq dan meruaq yang diperuntukkan kepada Puang Matua, ilah-ilah, dan dewata. Tujuan upacara ini adalah untuk memohon kesuburan tanah dan memudahkan interaksi sosial masyarakat dengan cara mengorbankan seekor kerbau muda hitam, gemuk, dan tambun. Himne Pasomba Tedong disajikan dalam bentuk prosa lirik.

Himne Pasomba Tedong sangat kaya dengan unsur budaya yang banyak mengandung nilai-nilai budaya yang masih eksis digunakan sampai sekarang. Himne Pasomba Tedong mengandung makna dan sistem pola pikir orang Toraja, sistem kepercayaan, serta sistem kemasyarakat sebagai falsafah hidup dan kehidupan suku bangsa Toraja. Ungkapan dan simbol-simbol itu menggambarkan kaitan dan hubungan, di antaranya dengan nilai religi, sistem nilai edukatif, nilai sosial, dan tata krama. Sehubungan dengan itu, upaya mengungkap nilai-nilai apa saja yang terkandung dalam himne Pasomba Tedong dirasakan sangat perlu untuk mewujudkan kerukunan hidup antara umat beragama yang sejati, harus tercipta satu konsep hidup yang mengikat semua anggota kelompok sosial yang berbeda agama untuk menghindari terjadinya konflik antar umat beragama.

Untuk mengetahui lebih mendalam tentang nilai-nilai Islam dan konsep Himne Pasomba Tedong di atas, perlu kajian lebih serius, sistematik dan radikal. Karena itu, kajian ini sangat menarik, bahkan sangat signifikan. Manfaatnya antara adalah sebagai kontribusi pemikiran kepada pemerintah daerah, tokoh adat, tokoh agama, pakar dan cendekiawan Muslim dalam membuat kebijakan untuk menata pembangunan masyarakat toraja yang damai, adil, bijak, dan sejahtera.

${ }^{1}$ Veen, van der, The Merok feast of the Sa'dan Toraja, (Gravenhage: Martinus Nijhoff., 1965), 18. Lihat juga Y. A. Sarira, Rambu Solo’dan Persepsi Orang Kristen tentang Rambu Solo' (Tana Toraja: Pusbang Gereja Toraja, 1996), 63. 
Kerangka teori yang dibangun dalam kajian ini adalah berdasarkan teori yang dikembangkan oleh Emile Durkheim ${ }^{2}$ yang melihat pembangunan masyarakat sebagai suatu yang damai, maju, bergerak, berkembang, saling interaksi dan solidaritas sosial. ${ }^{3}$

Berdasarkan teori ini, penulis menggunakan teori Durkheim untuk melihat nilai-nilai adat dan agama dari sudut fungsinya. Di samping itu, teori Durkheim sangat signifikan untuk membangun masyarakat toraja, karena salah satu faktor utama pembangunan masyarakat toraja adalah tidak terlepas dari selarasnya adat/budaya dan agama (Syariat Islam).

Di samping teori Durkheim, penulis juga menggunakan kerangka teori sosiologis dan antropologis yang dikemukan oleh Ibn Khaldun (w. 809/1406), ${ }^{4}$ yang berkaitan dengan fungsi organisasi masyarakat. Menurut teori Ibn Khaldun, organisasi masyarakat menjadi suatu keharusan bagi manusia (ijtimâ' daruryn li an-nawâ' alinsân). Tanpa orgnanisasi itu, eksistensi manusia tidak akan sempurna. Keinginan Tuhan hendak memakmurkan dunia dengan makhluk manusia, dan menjadikan mereka khalifah dipermukaan bumi ini tentulah tidak akan tebukti. Inilah arti yang sebenarnya dari nilai-nilai pembangunan dan peradaban ('ûmrân) yang dijadikan pokok pembicaraan ilmu pengetahuan yang selalu diperbincangkan atau didialogkan. Oleh karena itu, tulisan ini bertujuan untuk mendeskripsikan eksistensi Islam dan budaya lokal sebagai aktualisasi kearifan lokal yang terdapat dalam syair Toraja serta relevansinya dengan Pendidikan Islam

\section{PEMBAHASAN}

\section{A. Suku Toraja}

Tana Toraja di kenal dengan landskap budayanya (cultural landscape) yang unik, di antara yang paling khas yaitu adanya tradisi penguburan jenazah leluhurnya pada tebing batu. Keunikan budaya Toraja menjadikan wilayah ini dinominasikan menjadi UNESCO Work Heritage Sites, pada tahun 1995 yang lalu. Nilai dan daya tarik budaya yang ada juga menjadikan Tana Toraja sebagai daerah tujuan wisata utama kedua setelah pulau Bali, khususnya bagi wisatawan mancanegara.

${ }^{2}$ Durkheim was born in 1858 in the town of Efinal, near Strasbourg in north eastern France.His father was a rabbi, and as a young boy he was also strongly affected by a schoolteacher wasRoman Catholic. These influences may ave contributed something to his general interest in religious endeavors, but they did not make him personally a believer. By the time he was a yong man, he had become an a brilliant agnostic. Daniel L. Pals, Seven Theories of Religion (New York: Oxford University Press, 1996), 89-90.

${ }^{3}$ Emile Durkheim begitu terkesan oleh kemampuan agama dalam memelihara kesatuan sosial atau dalam menyatukan masyarakat (kelompok), sehingga ia membangun teori tentang agama sekitar itu. Ia melihat di balik keanekaragaman ritual, simbol dan kepercayaan agama terdapat karakteristik yang mendasari semua agama, dan berkesimpulan bahwa "the idea of society in the soul of religions". Lihat, Durkheim dalam L. Brom \& Philip Selzinic, Dorothy Darroch, Sosiology (New York: Harper \& Row Publisher, 1981), 399.

${ }^{4}$ Nilson Crocia Barros, Ibn Kaldun, a Dinâmica dos Assentamentos Humanos e as Funções Urbanas no Islã Histórico, (Mercator: Revista de Geografia da UFC, 2005), 4(8), 7-14. 
Selanjutnya, berdasarkan kriteria dan kelayakan yang dimiliki oleh budaya Toraja, maka UNESCO dalam konferensi World Heritage Cultural yang dilaksanakan di Hotel Missiliana pada 22 April 2001 berkeputusan "Bahwa dalam upaya pelestarian peninggalan kepurbakalaan budaya dan alam Toraja yang unik dan langka, maka daerah ini perlu dimasukkan dalam daftar kawasan wisata budaya dunia." Hasil konferensi tersebut kemudian dibuatkan rekomendasi oleh Bupati Tana Toraja nomor 556/0150/Pariwisata tanggal 29 Januari 2004. Rekomendasi tersebut ditujukan kepada DPRD Tana Toraja. Isinya agar DPRD membuat Surat Keputusan bahwa Tana Toraja sebagai kawasan warisan budaya dunia. Penetapan ini selanjutnya akan menjadi bahan pertimbangan Unesco untuk penetapan selanjutnya. ${ }^{5}$

Mayoritas orang-orang masih mengikuti sebuah kultur leluhur yang disebut "Aluk Todolo" yang mengatur semua upacara adat. Pola pelaksanaan Aluk Todolo yang dianut oleh masyarakat Toraja dilakukan dalam pemahaman dua sistem berjenjang dalam kehidupan manusia di dunia ini, pertama tantangan kesenangan, kebahagiaan, dan keselamatan; kedua tantangan kesusahan, kematian, dan kehancuran. ${ }^{6}$

Dari dua pemahaman tersebut, kepercayaan masyarakat Toraja yang dikenal dengan aluk terbagi ke dalam dua sistem dasar, pertama aluk tuka' yang berarti keberuntungan atau keselamatan dan kedua aluk solo' yang berarti kemunduran atau kegelapan. Maka seluruh aspek kehidupan masyarakat Toraja selalu dikaitkan dengan kedua pola sistem tersebut, yang sebagian besar implementasinya dapat terlihat pada upacara maupun ritual adat masyarakat Toraja. Budaya animisme mereka adalah salah satu dari banyak upacara, termasuk yang paling dikenal, yang berpusat pada kerbau. Hewan ini memainkan peran penting dalam kehidupan Toraja, yang merupakan simbol status dan juga merupakan simbol kurban disembelih pada upacara keagamaan seperti upacara pemakaman. Daya tarik lain yang dimiliki oleh Tana Toraja adalah 'Tao Tao,' yaitu kuburan gantung yang terletak di tebing yang dipotong dari batu-batu sebagai cara untuk mencegah kejahatan umum menjarah kuburan.

Budaya animisme mereka adalah salah satu dari banyak upacara, termasuk yang paling dikenal, yang berpusat pada kerbau. ${ }^{7}$ Hewan ini memainkan peran penting dalam

${ }^{5}$ Mohammad Natsir Sitonda, Toraja Warisan Dunia (Cet. III; Makassar: Pustaka Refleksi, 2009), 26. Lihat juga Anastasa Baan, Pesan Budaya dalam Tuturan Kada Tominaa Di Kabupaten Tana Toraja, Litera. 2015;14(2). Sofyan Salam, Muh. Saleh Husain, Tangsi the Symbolic Meanings of Toraja Carving Motifs, Panggung. 2017;27(3). Fransiskus Randa, Fransiskus E. Daromes, Transformasi Nilai Budaya Lokal dalam Membangun Akuntabilitas Organisasi Sektor Publik, Jurnal Akuntansi Multiparadigma. 2014;5(3):477-484.

${ }^{6}$ Abd. Kadir M, Kehidupan Masyarakat Kristen Protestan di Kelurahan Rantepao Kecamatan rantepao Kabupaten Tana Toraja dalam Bunga Rampai Penelitian Agama III (Ujung Pandang: Balai Penelitian Lektur Keagamaan, 1996), 26.

${ }^{7}$ Stanislaus Sandarupa, Glokalisasi Spasio-Temporal Dalam Agama Aluk To Dolo Oleh Agama Kristen Di Toraja, Sosiohumaniora, (Volume 17 No. 1 Maret 2015: 86 - 93), 87. Lihat juga, Sakirman, Islam Aboge dalam Tradisi Jawa Alastua, (IBDA': Jurnal Kebudayaan Islam. 2016), 14(2), 172-187. Muhammad Al Mujabuddawat, Simbolisme Kompleks Bangunan Situs Ki Buyut Trusmi Cirebon, 
kehidupan Toraja, yang merupakan simbol status dan juga merupakan simbol kurban disembelih pada upacara keagamaan seperti upacara pemakaman. ${ }^{8}$ Daya tarik lain yang dimiliki oleh Tana Toraja adalah 'Tao Tao,' yaitu kuburan gantung yang terletak di tebing yang dipotong dari batu-batu sebagai cara untuk mencegah kejahatan umum menjarah kuburan.

Daerah Tana Toraja merupakan salah satu daerah tujuan wisata andalan yang ada di Sulawesi Selatan. Tidak hanya memiliki alam yang eksotis, Tana Toraja juga memiliki budaya yang unik dan sarat akan nilai yang ada di dalamnya. Toraja kaya akan sastra, baik berupa cerita, maupun berupa syair. Tana Toraja mendiami wilayah pegunungan di Sulawesi Selatan. Penduduknya berjumlah sekitar 450.000 jiwa yang masih tinggal di Kabupaten Toraja Induk dan Kabupaten Toraja Utara. Umumnya, penduduk Toraja menganut agama Kristen dan sebagian lagi memeluk agama Islam serta sebagiannya lagi masih ada yang menganut kepercayaaan animisme yang dikenal dengan Aluk To Dolok. ${ }^{9}$

Agama Kristen Protestan yang merupakan agama mayoritas masuk di Tana Toraja berasal dari negeri Belanda. ${ }^{10}$ Pada tanggal 6 Februari 1901 di Utrecht Belanda Gereja Hervormd Belanda (Nederland Hervormd de Kerk) membentuk badan zending yang bernama de Gerevormeerde Zendings Bond (GZB). ${ }^{11}$ Maksud dari pada badan ini ialah untuk mengutus zendeling-zendeling yang membawakan sabda Tuhan kepada bangsa-bangsa yang belum mengenal Yesus Kristus. ${ }^{12}$

Sastra di Sulawesi Selatan, khususnya sastra Toraja berfungsi sebagai alat budaya masyarakatnya. Sebagai hasil budaya, sudah seharusnya sastra tersebut senantiasa dipelihara dan dibina, baik secara langsung, maupun tidak langsung.

(Kapata Arkeologi : 2016), 12(2), 175-190. Tengku Syarfina, Sinkretisme dalam Jampi Melayu Deli: Tinjauan Transformasi Budaya, (Atavisme : 2011), 14(1), 29-40.

${ }^{8}$ Nooy-Palm, The Sa'dan Toraja: a study of their social life and religion. Rituals of the east and west, (Dordrecht: Foris Publications. 1986). Lihat juga Imam Indratno, Sudaryono Sudaryono, Bakti Setiawan, Kawik Sugiana, Silau'na Tongkonan Sebagai Sebuah Realitas Tondok, (Ethos: Jurnal Penelitian dan Pengabdian kepada Masyarakat, 2016), 0(0), 75-84.

${ }^{9}$ Ratnawati, Badong, Puisi Duka Toraja: Bertahan di Tengah Arus Globalisasi, (Prosiding Seminar Internasional Pelantra, Universitas Adibuana PGRI Surabaya, 2009). Lihat juga Harry Wiriadinata, A new species of Begonia (Begoniaceae) from South Sulawesi, Indonesia, (Reinwardtia : 2013), 13(5), 445-448. Hamka, Antariksa, Lisa Dwi Wulandari, Karakteristik Orientasi Rumah Tradisional Bugis (Bola Ugi) di Dusun Kajuara Kabupaten Bone Sulawesi Selatan, (Langkau Betang: Jurnal Arsitektur, 2015), 2(2), 94-107. Bulu', Pendidikan Agama Islam Dalam Membendung Pengaruh Ajaran Aluk Todolo Di Tana Toraja Sulawesi Selatan, (Jurnal Pendidikan Agama Islam : 2016), 4(2), 179-205.

\footnotetext{
${ }^{10}$ Yan Malino, Daniel Ronda, Sejarah Pendidikan Sekolah Kristen Gereja Toraja suatu Kajian Historis Kritis tentang Peran Gereja Toraja Melaksanakan Pendidikan Sekolah Kristen dari Masa Zending Sampai Era Reformasi, (Jurnal Jaffray : 2014), 12(1), 35-70.

${ }^{11}$ Den Van End, Sumber-sumber zending tentang sejarah gereja Toraja 1901-1961, (Jakarta: PT BPK Gunung Mulia, 1994), 65.

${ }^{12}$ La Sakka, Pemetaan Lektur Klasik Kristen di Tana Toraja (Mapping Classical Christian Literatur In Tana Toraja) (Jurnal Balai Litbang Agama Makassar, Naskah 9 Oktober 2012).
} 
Pembinaan secara langsung dilakukan dengan cara menginventarisasi dan mendokumentasikan sejumlah sastra lisan yang masih tersebar luas di kalangan masyarakat Toraja.

Himne menurut adalah nyanyian pujaan untuk Tuhan dan sebagainya; gita puja. Himne Pasomba Tedong merupakan semacam prosa liris yang dinyanyikan pada saat upacara syukuran kepada Tuhan, yaitu upacara maqbuaq dan meruaq. Di dalam himne Pasomba Tedong terdapat ungkapan dan simbol yang mengandung nilai-nilai sebagaimana yang terdapat dalam kehidupan sehari-hari, di antaranya nilai religi, nilai edukatif, nilai sosial, dan nilai tata krama.

Himne Pasomba Tedong terdiri atas empat babak. Pada babak pertama terdapat uraian sejarah asal-usul aluk, pemali, dan kerbau, termasuk penetapan kerbau toseko sebagai kerbau pilihan untuk dipersembahkan kepada Puang Matua. Pengucapan dalam pelaksanaannya berupa himne pujaan berbentuk prosa berirama. Pada babak kedua, tomasomba (orang yang akan melaksanakan kegiatan Pasomba Tedong) menyucikan atau membersihkan kerbau korban yang akan dipersembahkan. Babak ketiga disebut maqmammang (mangimbo), yakni permohonan menghadirkan Puang Matua, ilah-ilah, dan dewata untuk menerima persembahan.

Bahasa yang dipergunakan merupakan bahasa puitis, berbentuk prosa berirama, tetapi intonasi dan aksennya mengalami perubahan, kedengarannya seperti monoton tapi lebih keras dari babak sebelumnya. Dalam pengucapan dan penampilannya, tomasomba seperti mengucapkan mantra yang memiliki kekuatan gaib. Babak keempat disebut mappasakkeq yang merupakan puncak upacara merauq padang.

Pada babak ini terdapat pengucapan untuk saling memberkati satu sama lain dan mengukuhkan ikatan janji. Pada babak ini terdapat penegasan kembali untuk memohon kepada Puang Matua, ilah-ilah, dan dewata untuk memohon kesuburan lembah persawahan.

Syair-syair Toraja adalah syair yang diungkapkan oleh masyarakat Toraja pada pergaulan sehari-hari. Syair-syair ini dapat diungkapkan oleh seorang pemuda kepada kekasihnya, seorang nenek yang sedang menidurkan cucunya, seorang perantau yang rindu akan kampung halamannya. ${ }^{13}$ Berikut ini disajikan beberapa contoh syair dalam bahasa Toraja.

Kenna tang manuk maramba

Asunna memongka-mongka

Kamimo kami dikkaq

Rampo tang dikambaroan

Terjemahan:

Andai bukan ayam ribut

Anjingnya yang menyalak

Kamilah kasihan

Datang tak ditegur

\footnotetext{
${ }^{13}$ Jemmain dan Hastianah, Syair-Syair Sastra Toraja, (Jakarta: Pusat Pembinaan dan Pengembangan Bahasa, Depdiknas, 1999), 1.
} 
Masussa napaqdiq tongan

Situmae tau mambela

Anna ratu dio mai

Mata tangsitarruq pessaile silambi

Terjemahan:

Amatlah susah

Bertunangan orang jauh

Bila bicara

Mata ditundukkan, menoleh pun tidak

Iya sia raka iti

Susi todianna inde

Mamaliqna allo bongi

Innang makassing issinna

Terjemahan:

Apakah sama di situ

Seperti di hati ini

Aku rindu siang malam

Bagus sekali isinya.

\section{B. Nilai-Nilai Islam}

Dasar-dasar ajaran Islam yang meliputi aqidah, syari'ah dan akhlaq

1. Aqidah

Pada dasarnya manusia membutuhkan kepercayaan, kepercayaan itu akan membentuk sikap dan pandangan hidup seseorang. Kepercayaan atau keimanan merupakan pondasi utama yang akan menentukan sikap seseorang dengan keimanan yang tertanam dalam diri seseorang. Maka segala amal perbuatannya ditunjukan untuk memenuhi perintah Tuhan dan menjauhi segala larangan-Nya. Objek keimanan yang tidak akan berubah manfaatnya dan tidak akan pernah hilang adalah keimanan yang ditentukan oleh agama. ${ }^{14}$ Dalam agama Islam ada macam pokok keimanan yang disebut rukun iman, yaitu: iman kepada Allah, iman kepada malaikat, iman kepada kitab-kitab, iman kepada Rasul, iman kepada hari akhir dan iman kepada Qodho dan Qadar atau takdir. ${ }^{15}$

2. Syari'ah

Menurut Mahmud Syaltout dalam bukunya Al-Islam Aqidah wa Al-Syaari'ah, yang dikutip oleh Zuhairini dkk, mengemukakan pengertian syariah sebagai berikut:

Syari'ah adalah peraturan-peraturan yang diciptakan Allah atau yang diciptakan pokok-pokoknya supaaya manusia berpegang teguh kepadanya didalam hubungannya

\footnotetext{
${ }^{14}$ Muhammad Hidayat Ginanjar \& Nia Kurniawati, Pembelajaran Akidah Akhlak dan Korelasinya dengan Peningkatan Akhlak al-Karimah Peserta Didik, (Edukasi Islami: Jurnal Pendidikan Islam, 2017), 6(12).

${ }^{15}$ Amelia Atika, Model Bimbingan Kelompok Berbasis Rukun Iman untuk Mencegah Kenakalan Remaja, (Psikopedagogia: Jurnal Bimbingan dan Konseling, 2016), 5(2). Lihat juga Tri Haryati, Kematangan Beragama Masyarakat Industri Batik, (Jurnal Penelitian: 2017), 13(2).
} 
dengan Tuhan-Nya dengan kehidupannya. ${ }^{16}$ Berdasarkan pada pengertian di atas, syari'ah berpusat pada dua segi yang mendasar, yaitu segi hubungannya dengan tuhan yang disebut ibadah, dsn segi hubungan manusia dengan sesama yang di sebut muamalah. Antara ibadah dan muamalah mempunyai kaitan yang sangat erat, tidak dapat dipisahkan antara yang satu dengan yang lainnya, dalam arti keduanya harus bernilai ibadah sebagai proses, sesuai dengan maksud dan tujuan manusia diciptakan Tuhan. Seperti dalam firman Allah Q.S. Surat Adz-Dzariyat/51: 56.

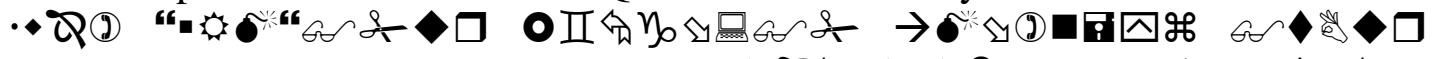

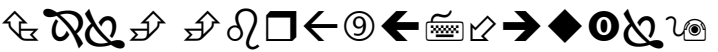

Terjemahnya: "Dan aku tidak menciptakan jin dan manusia melainkan supaya untuk mengabdi (ibadah) kepada-Ku”.

\section{Akhlak}

Akhlak dari segi bahasa berasal dari bahasa Arab yang berarti perangai, tabiat, watak dasar kebiasaan, sopan dan santun agama. Secara linguistik (kebahasaan) kata akhlak merupakan isim jamid atau isim ghairu mustaq, yaitu isim yang tidak mempunyai akar kata, melainkan kata tersebut memang begitu adanya. Kata akhlak adalah jama dari kata khuluqun atau khuluq yang artinya sama dengan arti akhlaq sebagaimana telah disebutkan di atas. ${ }^{17}$

Dengan melihat arti pendidikan Islam di atas, jelaslah bahwa dengan pendidikan Islam berusaha untuk membentuk manusia yang berkepribadian kuat dan baik (akhlakul karimah) berdasarkan pada ajaran agama Islam. Oleh karena itulah, pendidikan Islam sangat penting sebab dengan pendidikan Islam, dapat mengarahkan masyarakat untuk membentuk kepribadian yang sesuai dengan ajaran Islam. Aspek pembelajaran pendidikan agama Islam meliputi pemahaman, penyikapan dan pengimplementasian. Dalam subbab ini akan dibahas satu persatu mengenai efektifitas aspek-aspek pembelajaran tersebut.

\section{RELEVANSI NILAI-NILAI KEARIFAN LOKAL DALAM SYAIR DENGAN PENDIDIKAN ISLAM}

Nilai-nilai budaya yang terkandung dalam himne Pasomba Tedong. Nilai-nilai tersebut, di antaranya adalah sebagai berikut:

\section{1) Nilai Religi}

Di dalam himne Pasomba Tedong terdapat nilai religi atau keagamaan. Hal ini terlihat pada lirik himne yang mengungkap kata-kata yang berhubungan dengan

${ }^{16}$ Zuhairini, Filsafat Pendidikan Islam, (Jakarta: Bumi Aksara, 1995), 36.

${ }^{17}$ Moh. Ardani, Akhlak Tasawuf Nilai-Nilai Akhlak atau Budipekerti dalam Ibadah dan Tasawuf, (Jakarta: Karya Mulia, 2005), 25. Lihat juga Nurhayati, Akhlak dan Hubungannya Dengan Aqidah Dalam Islam, (Jurnal Mudarrisuna: Media Kajian Pendidikan Agama Islam, 2014), 4(2):289309. 
ketuhanan seperti Puang Matua tomegaraga, tomekombong, tometanpa torro tolinoyang artinya 'Puang Matua yang membuat, membentuk, dan menempa manusia'. Contoh:

(1) Batiqna pundu Toseko la misorong langan Puang Matua jao tangana langiq, Puang metampa kumombong torro tolino. Misorongi langan puang Toqbonaq, Toqkumpang jao Toqtandung siliuan (Larik 7.1.2).

'Turunan pundu Toseko akan kamu serahkan kepada Puang Matua di atas langit, ilah membuat, penjunjung manusia. Kamu serahkan kepada ilah Tobenaq, Toqkumpang, dan Toqtandung (nama tempat).'

Pada contoh 1 tersebut terdapat himne yang menyebutkan kata Puang Matua yang berarti Tuhan. Hal ini menandakan bahwa orang Toraja mempunyai kepercayaan kepada Tuhan Sang Pencipta Alam yang menciptakan manusia beserta alam jagat raya. Pada contoh ini terdapat beberapa tempat yang disebutkan untuk diberkahi sebagai tempat persawahan, yaitu daerah Tobenaq, Toqkumpang, dan Toqtandung.

(2) Puang Matua jao tangana langiq, puang parande pajujung jiong mangapiqna tana, langanmo dirandan taqkamali alukna pemali alukna sumalunna Lombok, rokkonna dibille tokayangan jiong tilampan tikalobona (Larik 9.1).

'Puang Matua di atas tengahnya langit di bawah pusaran tanah, ke atas dikerjakan teratur pemali alukna lembahnya persawahan, ke udik disebar penjaga gadis di bawah hamparan persawahan. Pasomba Tedong yang menggambarkanbahwa Tuhanlah yang maha mengatur segala urusan manusia, termasuk urusan kesuburan tanah persawahan.

(3) Keqde di neneq maumi batiqna sambao bangiq dipengongoran langan Puang Matua jao tangana langiq tempon tojolomumo dipekaduan rokko puang parande pajujung jiong mangapiqna tanaanna lan merrantena lino (Larik, 13). Kusanga masinanglaqmo tutu batangmu disorong langan Puang Matua jao tanganna langiq masindungmo lan paqinawannmu dipirikan rokko biring karraqna Puang parande pajujung jiong mangapiqna tana (Larik 14.1).

'Mulai dari nenekmu turunan kerbau kelabu diperhadapkan kepada Puang Matua di atas tengahnya langit, sejak leluhurmu diserahkan dua buah tangan dipersembahkan kepada ilah penantang penjunjung di bawah pusaran tanah dan ilah di dataran bumi. Saya yakin jelaslah kedudukan dipersembahkan kepada Puang Matua di atas, tengahnya langit, sudah lapang dalam hatimu dijatuhkan ke bawah pembuluh kerasnya ilah penentang penjunjung dan ilah di atas dataran bumi.'

\section{2) Nilai Persatuan}

Merauq padang atau massomba tedong tidak dilaksanakan secara perorangan, tetapi dilakukan oleh suatu keluarga besar. Keluarga tersebut rela berkorban untuk kepentingan bersama. Mereka memohon berkat untuk kesuburan lembah persawahan 
karena cinta kepada kampung halaman, cinta kepada tanah air. Hal ini dapat disimak dalam himne berikut:

(4) Nagaragami kombongan kalua' Sullena neneq lan padang di Sillanan Nakombonganmi sitinjo tomamawa solon tarapangna Todipotau bunga lan Tongkonan Karua (Larik 32.3)

'Dilaksanakanlah musyawarah luas pengganti nenek (leluhur) dalam daerah Sillanan dimusyawarahlah sepadan kekuatan pengganti (wakil) manusia pemula dalam Tongkonan Karua.' Himne ini menggambarkan tentang adanya kerja sama atau persatuan berupa musyawarah pada masyarakat khususnya di daerah Sillanan. Adanya sikap seperti ini tentu saja patut dicontoh oleh masyarakat untuk menciptakan kehidupan yang harmonis.

Persatuan tidak hanya berlaku untuk suatu wilayah tertentu, tetapi berlaku lebih luas ke seluruh wilayah Lepongan Bulan (Tana Toraja yang terkenal dengan ungkapan "Misa kada dipotuo pantan kada dipomate" yang artinya 'Satu pendirian menyelamatkan, masing-masing pendirian meruntuhkan.'

Ikatan janji dinamakan basse yang terdiri atas tiga bagian berikut:

1. Batu bontomanae sebanyak tiga buah ditancapkan dalam lokasi Tongkonan Karua. Batu ini dibawa dari Gowa oleh Somba ri Gowa. Penancapan batu bontomanae adalah perjanjian antara Tinti ri Buntu (penguasa di daerah Sillanan) dengan Somba ri Gowa. Isi perjanjiannya mengungkapkan bahwa masyarakat Sillanan mengikat janji persaudaraan dengan masyarakat Gowa melalui pimpinan mereka.

2. Tanaman basse (tancapan janji) ditanam di lokasi Tongkonan Karua. Isi perjanjiannya menyatakan bahwa masyarakat Sillanan menggalang persaudaraan dengan masyarakat Enrekang. Hal ini tercermin dalam ungkapan "Sillanan jiong, Endekang inde" yang artinya 'Sama hak, sama derajat, dan saling menjamin keamanan bersama.'

3. Tatu Tallu di Simbuang ditancapkan di Simbuang, Tana Toraja. Tancapan batu ini adalah janji (basse) antara Toraja, Mamasa, Mandar, dan Bugis Sawitto. Isi perjanjiannya menyatakan bahwa di antara mereka tidak akan menimbulkan permusuhan dan bertekad bersatu dan bersama-sama menentang jika ada gangguan yang mengancam.

\section{3) Nilai Etis}

Manusia dibekali kemampuan oleh pencipta untuk mengembangkan diri agar menjadi pribadi dan anggota masyarakat yang baik. Norma-norma yang tercakup dalam aluq dan pemali, di samping norma lain, muncul dan disepakati dalam dinamika interaksi sosial masyarakat setempat. Berikut penjelasan beberapa pemali beserta sanksinya.

(5) Pemali sibali sile'tota

'Dilarang kawin dengan saudara sekandung' 
Adanya pemali ini akibat dari pernikahan terlarang antarsaudara, yaitu londong di langit dengan londong di ruraq. Sementara pesta perkawinan berlangsung, Puang Matua marah, lalu menjatuhkan hukuman dalam bentuk musibah. Lokasi tempat diadakan pesta perkawinan akhirnya runtuh lalu berubah menjadi kolam yang hingga saat ini masih ada bekasnya. Dengan demikian, sikap pemali untuk menikah dengan saudara kandung sampai saat ini masih diyakini dan apabila hal itu terjadi tentu saja akan menjadi aib bagi keluarga tersebut.

(6) Pemalik umpatingarai bulan, pemali umpaqpalindaqi padan

'Petunjuk untuk tidak berbuat semberono dalam hubungan seks'

Umpantingarai bulan berarti tidur terlentang menghadap bulan. Arti yang terkandung menunjukkan bahwa perbuatan melakukan hubungan suami istri yang dilakukan di luar ruangan, dalam hal ini di tengah padang. Selanjutnya ungkapan umpaqpalindaqi padang berarti tanah yang dijadikan landasan. Arti yang dikandungnya menunjuk pada perbuatan hubungan intim di luar rumah, berlangsung di tengah padang. Adapun akibat dari perbuatan ini menyebabkan tanah menjadi tandus, pertanian tidak berhasil, dan malapetaka bagi umat manusia.

Dalam masyarakat toraja pemali merupakan suatu perbuatan yang tidak boleh dilakukan karena dapat menimbulkan rasa malu atau siri namun masyarakat toraja menyebutkan longko', namun karakteristiknya berbeda dengan budaya siri' sebagaimana yang dipahami oleh orang Bugis, meski orang Toraja sering meminjam istilah tersebut dari bahasa Bugis.

Toraja may even borrow the word siri' to talk about their own particular complex of honour and shame, but it is clear from my discussion with informants that longko' is characteris- tically different from Bugis siri'. Longko' refers as much to sense of shame felt in relation to other family members as to feelings between families. Feelings of shame (kalongkoran) may be provoked not only by public attack on an individual's honour by someone else, as among Bugis, but equally by a sense of one's own failure to do the right thing, especially if one then feels the scorn of other family members. ${ }^{18}$

Longko' bukan hanya mencakup rasa malu dan harga diri, tetapi juga menyangkut tenggang rasa, yaitu tentang keharusan seseorang untuk bersikap sopan dan hormat untuk tidak mempermalukan orang lain. Seseorang sebaiknya tidak mempermalukan orang lain karena akan mempermalukan diri sendiri. Tae' na dibatang dallei tu tau (kata-kata itu sebaiknya tidak telanjang seperti batang jagung), artinya tidaklah santun untuk menyatakan secara terang-terangan tentang sesuatu kepada seseorang kalau hal itu dapat menyakiti atau mempermalukan orang tersebut. Budaya malu atau shame culture dari perspektif Antropologi sering dipahami sebagai budaya yang besifat statis, tidak produktif, ketinggalan di bidang ekonomi serta tidak

\footnotetext{
${ }^{18}$ Houses Waterson Roxana, Graves and The Limits Of Kinship Grouping Among The Sa'dan Toraja, (Leiden: KITLV, 1995.), 212-213.
} 
memiliki norma-norma yang absolut. ${ }^{19}$ Budaya ini, namun demikian, apabila ditelaah lebih dalam dapat dijumpai nilai-nilai yang penting bagi kehidupan manusia Toraja.

Orang Toraja memahami bahwa jaring-jaring simbolik tidak hanya ditemukan dalam upacara ritual Rambu Tuka (ritual syukur atau suka cita) dan Rambu Solo (ritual pemakaman atau duka cita), tetapi juga dalam pemaknaan setiap pandangan hidup dan tutur mereka, sesuatu yang dipahami Volkman sebagai $a$ story they tell themselves about themselves. ${ }^{20}$

\section{4) Nilai Musyawarah untuk Mufakat}

Keinginan melaksanakan upacara merauk padang diawali dengan musyawarah yang dipimpin oleh orang yang dituakan. Dalam musyawarah tersebut, setiap keluarga menyatakan kesanggupan/kemampuannya. Akan tetapi, pemimpin musyawarah tetap memperhatikan dan menghargai keberadaan warga yang tidak melaksanakan keinginannya. Unsur mufakat dalam himne Pasomba Tedong dapat disimak pada uraian berikut:

(7) Garagaka tengko situruq bataka siolonan (Larik 30.6) 'Bentuklah persatuan'

Kombongko mesa inawa ilalan kombongan kalua (Larik 30.6,) 'Bersatulah dalam musyawarah' Tatulungan sumalunna lombok (Larik 30.6) 'Kita membuat persembahan untuk kesuburan persawahan.

Hasil musyawarah yang berupa kesatuan pendapat menjadi keputusan bersama serta untuk dilaksanakan bersama. Musyawarah pada masyarakat Toraja terdapat pada setiap kegiatan, antara lain ketika mendirikan rumah tongkonan dan upacara kematian. Kegiatan musyawarah ini sama halnya seperti pekerjaan turun ke sawah, menuai padi, membuat bendungan, dan menjaga keamanan. Salah satu himne yang berhubungan dengan nilai musyawarah adalah sebagai berikut.

8) Iko indoq lan te tondok Ambeq lan sangleon-leon Garagaiko situru Kombongko mesa inawa Namesa tengko narapaq Nabatakan siolanan Deqna bingaq karurungan Deqna ellakan beluak (Larik, 35).

Artinya:

Pimpinan dalam negeri ini Bermusyawarahlah, bersatulah seiring dalam bertindak agar kita hidup sejahtera Musyawarah yang besar pernah terjadi di Toraja, namanya Musyawarah Topada Tindo yang artinya sama derajat, tidak seorang pun yang memaksakan kehendak, sama hak, dan tidak saling meremehkan. Hal ini terjadi pada tahun 1970. Pesertanya terdiri dari wakil-wakil Tongkonan Layuk sebanyak 120 orang. Hasil Musyawarah Topada Tindo adalah sebagai berikut.

\section{Mesa kada dipotuo pantan kada dipomate.}

${ }^{19}$ Margaret Mead, Cooperation and Competition among Primitive People, (Boston: Beacon Press., 1961), 458-511

${ }^{20}$ Toby A Volkman, Feast of Honor: Ritual and Change in the Toraja Highlands, ( Chicago: University of Illinois Press, 1985), h. 7. Dilihat Clifford Geertz, The Interpretation of Cultures, (New York: Basic Books, Inc., 1973), 448. Yonatan Sumarto, Peter Anggu, Pembinaan Kerohanian Gereja Bethel Tabernakel dalam Konteks Kebudayaan Toraja, (Jurnal Jaffray: 2010), 8(1), 24-34. 
'Satu pendirian menyelamatkan, masing-masing pendirian meruntuh.

\section{5) Nilai Tenggang Rasa dan Saling Menghormati}

Nilai tenggang rasa terdapat juga pada himne Pasomba Tedong. Nilai tersebut terdapat pada himne berikut ini:

(9) Banjan sipatuo baloq sipatumumbu kumukuq unnoqkoq tang sirio langgaq lumingka tang sisembaq kalo-kalo. ${ }^{21}$

Berdiri saling menghormati saling menyelamatkan duduk tidak memangku menjatuhkan tidak menggendong tanpa simpulan berjalan. Pada contoh himne tersebut terkandung nilai budaya saling menghormati antarsesama umat manusia. Nilai ini masih tetap dipertahankan sampai sekarang dan masih eksis digunakan. Masyarakat Toraja mempunyai sifat tenggang rasa dan saling menghormati dalam kehidupan sehari-hari, apalagi untuk mengambil keputusan dalam mengadakan musyawarah pada saat mengadakan upacara besar seperti upacara kematian.

(10) Ammi lumokkonmo lalanmi puang parande pajujung rokko mangapiqna Tana benjan sipatuo baloq sulleqna neneq lan padang di Sillanan ammi sipatumumbu kumukuq solon tarapangna todipotau bungaq lan Toangkonan Karua taang sisembeq sirio langgaq tang sisembeq kalo-kal (Larik 39.4).

'Sudilah membalik jalananmu ilah penantang penjunjung ke bawah pusaran tanah berdiri saling menghormati penggantinya leluhur di daerah Sillanan saling menyelamatkan penggantinya manusia pemula dalam Tongkonan Karua tidak memangku menjatuhkan tidak menggendong tanpa simpulan.'

Nilai budaya saling menghormati juga terdapat dalam himne Pasomba Tedong contoh 10. Nilai ini bertalian dengan sikap masyarakat Toraja yang sudah ada sejak zaman leluhur mereka. Nilai ini sampai sekarang masih tetap dipertahankan dan dijaga dengan baik oleh masyarakat Toraja.

(11) Ammi andikku buntu rengeqmi jio laqbimi banua rengeqna sullena neneq anna andikki dukai buntuk rengeqna sullena neneq lan padang di Sillanan solon tarapangna todipotau bungaq lan Tongkonan Karua (Larik 39.6).

'Eratkanlah tali bebanmu di negeri mulia dan istana sucimu lalu dieratkan juga tali beban penggantinya leluhur di daerah Sillanan penggantinya manusia pemula dalam Tongkonan Karua.'

(12) Ammi benjan sipatuo baloq ammi tunannang sipatumumbu kumukuq tang sirio langgaq tang sisembe kalo-kalo (Larik, 39.7).

\footnotetext{
${ }^{21}$ Agus, Nuraidar.. "Refleksi Sosial Mitos Cerita Rakyat Toraja terhadap Perilaku Masyarakat Toraja Kini” (dalam kumpulan makalah), (Solo: Fakultas Sastra dan Seni Rupa Publishing, 2010), 97.
} 
Agar saling menghormati dan tetap saling menyelamatkan tidak memangku menjatuhkan tidak menggendong tanpa simpulan. Pada contoh 11 dan 12 nilai saling menghormati juga didapatkan pada himne Pasomba Tedong. Himne ini menggambarkan bahwa masyarakat sepatutnya mengeratkan tangan dan bersatu serta saling membantu. Sikap seperti ini sepatutnya dijaga dan dipertahankan karena dengan sikap seperti ini tali persaudaraan akan semakin erat.

Hubungan hukum adat dengan hukum agama sebagaimana dijelaskan oleh Tengku H. Abdullah Husni bahwa, hukum adat dan adat-istiadat menghukum bersifat wujud, artinya kata adat itu selaras dengan ketentuan hukum. Hukum menghukum bersifat kalam, artinya selaras dengan hâblûmînâllâh. Filsafat hukum ialah adat bersendikan syârâ',syârâ' bersendikan kepada adat. Maksudnya adalah adat-istiadat itu tidaklah akan kuat dan kokoh kalau sekiranya tidaklah bersumber kepada syârâ'. Hukum syârâ' tidaklah akan terwujud dan terealisasi serta menjadi kenyataan dalam kehidupan dan pembangunan masyarakat kalau tidak dijadikan hukum adat sebagai pendukungnya. ${ }^{22}$ Karena itu, nilai-nilai pembangunan masyarakat toraja tidak terlepas dari ketentuan hukum Islam dan adat-istidat/budaya masyarakat toraja, seperti; Puang Matua (Tuhan)" Kombongko mesa inawa ilalan kombongan kalua" (Bersatu dalam musyawarah), Topada Tindo yang artinya (sama derajat), Longko (Harga diri/Tenggang Rasa)

Oleh karena itu, walaupun mayoritas masyarakat toraja beragama kristen, tetapi tidak pernah terjadi konflik antara agama, ras, ataupun etnik ini dikarenakan faktor kearifan lokal tana toraja yang saling menghormati, menghargai dan tolong menolong sudah terbangun sejak nenek moyang mereka. ${ }^{23}$ Rumah Tongkonan menjadi pemersatu dari perbedaan yang ada pada masyarakat Toraja karena rumah Tongkonan adalah lambang pemersatuan bagi masyarakat Tana Toraja. Rumah Tongkonan bagi masyarakat Tana Toraja adalah seorang Ibu dan Alang Sura ${ }^{e e}$ (Lumbun Padi) adalah bapaknya, karena itulah mengapa masyarakat Tana Toraja sangat rukun meskipun berbeda agama.

Islam sebagai ajaran yang memuat nilai-nilai normatif, sarat dengan ajaran yang menghargai dimensi pluralis-multikultural begitu bagusnya dalam memandang dan menempatkan martabat dan harkat manusia, baik sebagai individu maupun sebagai

\footnotetext{
${ }^{22}$ Tengku H. Abdullah Husni, dalam Syukri, Sarakopat: Sistem Pemerintahan Tanah Gayo Dan Relevansinya Terhadap Pelaksanaan Otonomi Daerah (Jakarta: Hijri Pustaka Utama, 2006), 160.

${ }^{23}$ Sabil Mokodenseho \& Ismail S. Wekke., Toleransi Beragama dan Pembelajaran Agama Islam:Harmoni Masyarakat Minoritas Muslim Manado, (Prosiding Seminar Nasional \& Temu Ilmiah Jaringan Peneliti: IAI Darussalam Blokagung Banyuwangi, 2017), 67-75. Lihat juga Ismail Suardi Wekke, Sabil Mokodenseho, Firdaus, Religious Education and Tolerance: Learning Process in High School of Minority Muslim Indonesia, (Proceeding STEd: Fakulti Pendidikan UKM Malaysia, 2017), 137-141.
} 
anggota sosial. Diantara nilai-nilai Islam yang menghargai dimensi pluralismultikultural adalah: ${ }^{24}$

a. Konsep kesamaan/kesetaraan, yang memandang manusia pada dasarnya sama derajatnya. Satu-satunya pembedaan kualitatif dalam pandangan Islam adalah ketakwaan. Sehingga konsep inipun berlaku baik untuk laki-laki maupun perempuan, mereka sama di mata Tuhan.

Menurut Islam, seluruh manusia berasal dari satu asal yang sama, yaitu Nabi Adam dan Hawa. Meskipun nenek moyangnya sama, namun dalam perkembangannya kemudian terpecah menjadi bersuku-suku, berkaum-kaum atau berbangsa-bangsa, lengkap dengan segala kebudayaan dan peradaban khas masing-masing.

b. Konsep keadilan, yang berarti pengakuan dan perlakuan yang sama antara hak dan kewajiban.

Keadilan pada intinya terletak pada keseimbangan atau keharmonisan antara menuntut hak, dan menjalankan kewajiban. Adil harus dilakukan terhadap diri sendiri, keluarga, kelompok, dan juga terhadap lawan.

c. Konsep kebebasan/kemerdekaan, yang memandang semua manusia pada hakikatnya hanya hamba Tuhan saja, sama sekali bukan hamba sesama manusia. Berakar dari konsep ini, maka manusia dalam pandangan Islam mempunyai kemerdekaan dalam memilih profesi, memilih hobi atau minat, memilih wilayah hidup, bahkan dalam menentukan pilihan agama pun tidak dapat dipaksa.

d. Konsep toleransi (tasamuh) yang merupakan sikap membiarkan, mengakui dan menghormati keyakinan orang lain tanpa memerlukan persetujuan. Bahasa Arab menterjemahkan dengan "tasamuh", berarti saling mengizinkan, saling memudahkan.

Toleransi berarti membolehkan, membiarkan yang pada prinsipnya tidak perlu terjadi. Toleransi mengandung konsesi, artinya, pemberian yang hanya didasarkan kepada kemurahan dan kebaikan hati, bukan didasarkan kepada hak. Jelaslah bahwa toleransi terjadi dan berlaku karena terdapat perbedaan prinsip, dan dalam menghormati perbedaan atau prinsip orang lain itu hendaklah tanpa mengorbankan prinsip sendiri. Selain itu toleransi juga merupakan sikap menerima bahwa orang lain berbeda dengan dialog dan toleransi merupakan satu kesatuan yang tidak dapat dipisahkan. Bila dialog itu bentuknya, toleransi itu isinya. Toleransi diperlukan tidak hanya pada tataran konseptual, melainkan juga pada tingkat teknis operasional.

\section{KESIMPULAN}

Himne Pasomba Tedong merupakan semacam prosa liris yang dinyanyikan pada saat upacara syukuran kepada Tuhan, yaitu upacara maqbuaq dan meruaq padang.

${ }^{24}$ Yulia Riswanti, Urgensi Pendidikan Islam dalam membangun Multilkulturalisme, Jurnal Kependidikan Islam Fakultas Tarbiyah UIN Sunan KAlijaga Yogyakarta, 2008), 3(2), 31. Lihat Juga Ismail Suardi Wekke \& Sabil Mokodenseho, Tolerance Understanding and Religious Teaching and Learning in Minority Muslim of Manado North Sulawesi, (International Seminar on Islamic and Arabic Education in Shoutheast Asia, UMM: Malang, February 3-4, 2017). Ismail Suardi Wekke \& Sabil Mokodenseho, Religious Teaching and Learning in Minority Muslim of Manado Indonesia, (Proceeding ICEST Atlantis Press : 2017), 187-189. 
Tujuan utama upacara ini adalah untuk memohon kesuburan persawahan kepada Tuhan agar sawah yang digarap menghasilkan panen yang melimpah ruah. Di dalam himne Pasomba Tedong terdapat ungkapan dan simbol yang mengandung nilai-nilai yang terdapat dalam kehidupan sehari-hari. Nilai-nilai yang ditemukan dalam himne Pasomba Tedong adalah nilai religi atau ketuhanan, nilai persatuan, nilai musyawarah mufakat, nilai etis, nilai tenggang rasa, dan nilai saling menghormati.

Kearifan lokal tana toraja yang saling menghormati, menghargai dan tolong menolong sudah terbangun sejak nenek moyang mereka. Ungkapan-ungkapan masyarakat toraja sebagai salah satu nilai budaya adalah tingginya nilai sastra yang dikandungnya sehingga sulit difahami oleh generasi sekarang, maka perlu adanya upaya penerjemahan kedalam bahasa Indonesia. Selain itu kebudayaan sesungguhnya bukan sebagai syariat tetapi bisa menjadi syiar dalam pengembangan pendidikan dan dakwah Islam, sehingga menjadi tanggungjawab bersama khususnya para dai dan pendidik untuk menjelaskan kepada masyarakat agar dapat melestarikan dan mengaktualisasikan kembali serta dipertahankan oleh setiap generasi yang berganti.

\section{REFERENCE}

Agus, Nuraidar. "Refleksi Sosial Mitos Cerita Rakyat Toraja terhadap Perilaku Masyarakat Toraja Kini” (dalam kumpulan makalah), (Solo: Fakultas Sastra dan Seni Rupa Publishing, 2010).

Ardani, Moh. Akhlak Tasawuf Nilai-Nilai Akhlak atau Budipekerti dalam Ibadah dan Tasawuf, (Jakarta: Karya Mulia, 2005).

Atika, Amelia. Model Bimbingan Kelompok Berbasis Rukun Iman untuk Mencegah Kenakalan Remaja, (Psikopedagogia: Jurnal Bimbingan dan Konseling, 2016), 5(2).

Baan, Anastasa. Pesan Budaya dalam Tuturan Kada Tominaa Di Kabupaten Tana Toraja, (Litera: 2015), 14(2).

Barros, Nilson Crocia. Ibn Kaldun, a Dinâmica dos Assentamentos Humanos e as Funções Urbanas no Islã Histórico, (Mercator: Revista de Geografia da UFC, 2005), 4(8), 7-14.

Bulu', Pendidikan Agama Islam Dalam Membendung Pengaruh Ajaran Aluk Todolo Di Tana Toraja Sulawesi Selatan, (Jurnal Pendidikan Agama Islam: 2016), 4(2), 179-205.

Daniel L. Pals, Seven Theories of Religion, (New York: Oxford University Press, 1996), 89-90.

Departemen Agama RI, Al-Qur'an dan Terjemahannya, (Semarang: CV. Toha Putra Semarang, 2010).

Departemen Agama RI. al-Qur'an dan Terjemahnya, (Bandung: Ponegoro, 2010).

Durkheim dalam Brom, L. \& Selzinic, Philip. Dorothy Darroch, Sosiology, (New York: Harper \& Row Publisher, 1981).

End, Den Van. Sumber-sumber zending tentang sejarah gereja Toraja 1901-1961, (Jakarta: PT BPK Gunung Mulia, 1994).

Geertz, Clifford. The Interpretation of Cultures, (New York: Basic Books, Inc., 1973).

Ginanjar, Muhammad Hidayat \& Kurniawati, Nia. Pembelajaran Akidah Akhlak dan Korelasinya dengan Peningkatan Akhlak al-Karimah Peserta Didik, (Edukasi Islami: Jurnal Pendidikan Islam, 2017), 6(12).

Hamka., Antariksa., Wulandari, Lisa Dwi. Karakteristik Orientasi Rumah Tradisional Bugis (Bola Ugi) di Dusun Kajuara Kabupaten Bone Sulawesi Selatan, (Langkau Betang: Jurnal Arsitektur, 2015), 2(2), 94-107.

Haryati, Tri. Kematangan Beragama Masyarakat Industri Batik, (Jurnal Penelitian: 2017), 13(2).

Husni, Tengku H. Abdullah. dalam Syukri, Sarakopat: Sistem Pemerintahan Tanah Gayo Dan Relevansinya Terhadap Pelaksanaan Otonomi Daerah (Jakarta: Hijri Pustaka Utama, 2006). 
Indratno, Imam., Sudaryono., Setiawan, Bakti., Sugiana, Kawik. Silau'na Tongkonan Sebagai Sebuah Realitas Tondok, (Ethos: Jurnal Penelitian dan Pengabdian kepada Masyarakat, 2016), 0(0), 7584.

Jemmain dan Hastianah, Syair-Syair Sastra Toraja, (Jakarta: Pusat Pembinaan dan Pengembangan Bahasa, Depdiknas, 1999).

M, Abd. Kadir. Kehidupan Masyarakat Kristen Protestan di Kelurahan Rantepao Kecamatan rantepao Kabupaten Tana Toraja dalam Bunga Rampai Penelitian Agama III, (Ujung Pandang: Balai Penelitian Lektur Keagamaan, 1996).

Malino, Yan \& Ronda, Daniel. Sejarah Pendidikan Sekolah Kristen Gereja Toraja suatu Kajian Historis Kritis tentang Peran Gereja Toraja Melaksanakan Pendidikan Sekolah Kristen dari Masa Zending Sampai Era Reformasi, (Jurnal Jaffray: 2014), 12(1), 35-70.

Mead, Margaret. Cooperation and Competition among Primitive People, (Boston: Beacon Press, 1961).

Mokodenseho, Sabil \& Wekke, I. S. Toleransi Beragama dan Pembelajaran Agama Islam:Harmoni Masyarakat Minoritas Muslim Manado, (Prosiding Seminar Nasional \& Temu Ilmiah Jaringan Peneliti: IAI Darussalam Blokagung Banyuwangi, 2017), 67-75.

Mujabuddawat, Muhammad Al. Simbolisme Kompleks Bangunan Situs Ki Buyut Trusmi Cirebon, (Kapata Arkeologi: 2016), 12(2), 175-190.

Nooy-Palm, The Sa'dan Toraja: a study of their social life and religion. Rituals of the east and west, (Dordrecht: Foris Publications, 1986).

Nurhayati, Akhlak dan Hubungannya Dengan Aqidah Dalam Islam, (Jurnal Mudarrisuna: Media Kajian Pendidikan Agama Islam, 2014), 4(2):289-309.

Randa, Fransiskus \& Daromes, E. Transformasi Nilai Budaya Lokal dalam Membangun Akuntabilitas Organisasi Sektor Publik, (Jurnal Akuntansi Multiparadigma: 2014), 5(3):477-484.

Ratnawati, Badong, Puisi Duka Toraja: Bertahan di Tengah Arus Globalisasi, (Prosiding Seminar Internasional Pelantra: Universitas Adibuana PGRI Surabaya, 2009).

Riswanti, Yulia. Urgensi Pendidikan Islam dalam membangun Multilkulturalisme, (Jurnal Kependidikan Islam Fakultas Tarbiyah UIN Sunan Kalijaga Yogyakarta, 2008), 3(2), 31.

Roxana, H. W. Graves and The Limits Of Kinship Grouping Among The Sa'dan Toraja, (Leiden: KITLV, 1995).

Sakirman, Islam Aboge dalam Tradisi Jawa Alastua, (IBDA': Jurnal Kebudayaan Islam, 2016), 14(2), 172-187.

Sakka, La Pemetaan Lektur Klasik Kristen di Tana Toraja (Mapping Classical Christian Literatur In Tana Toraja), (Jurnal Balai Litbang Agama Makassar: Naskah 9 Oktober 2012).

Salam, Sofyan \& Husain, Muh. Saleh. Tangsi the Symbolic Meanings of Toraja Carving Motifs, (Panggung: 2017), 27(3).

Sandarupa, Stanislaus. Glokalisasi Spasio-Temporal Dalam Agama Aluk To Dolo Oleh Agama Kristen Di Toraja, (Sosiohumaniora: Maret 2015), 17(1):86-93.

Sarira, Y. A. Rambu Solo' dan Persepsi Orang Kristen tentang Rambu Solo', (Tana Toraja: Pusbang Gereja Toraja, 1996).

Sitonda, Mohammad Natsir. Toraja Warisan Dunia (Cet. Ill; Makassar: Pustaka Refleksi, 2009).

Sumarto, Yonatan \& Anggu, Peter. Pembinaan Kerohanian Gereja Bethel Tabernakel dalam Konteks Kebudayaan Toraja, (Jurnal Jaffray: 2010), 8(1), 24-34.

Syarfina, Tengku. Sinkretisme dalam Jampi Melayu Deli: Tinjauan Transformasi Budaya, (Atavisme: 2011), 14(1), 29-40.

Veen, van der, The Merokfeast of the Sa'dan Toraja, (Gravenhage: Martinus Nijhoff, 1965).

Volkman, Toby A. Feast of Honor: Ritual and Change in the Toraja Highlands, (Chicago: University of Illinois Press, 1985).

Wekke, I. S. \& Mokodenseho, Sabil. Religious Teaching and Learning in Minority Muslim of Manado Indonesia, (Proceeding ICEST Atlantis Press: 2017), 187-189. 
Wekke, I. S. \& Mokodenseho, Sabil. Tolerance Understanding and Religious Teaching and Learning in Minority Muslim of Manado North Sulawesi, (International Seminar on Islamic and Arabic Education in Shoutheast Asia, UMM: Malang, February 3-4, 2017).

Wekke, I. S., Mokodenseho, Sabil., Firdaus, Religious Education and Tolerance: Learning Process in High School of Minority Muslim Indonesia, (Proceeding STEd: Fakulti Pendidikan UKM Malaysia, 2017), 137-141.

Wiriadinata, Harry. A new species of Begonia (Begoniaceae) from South Sulawesi, Indonesia, (Reinwardtia: 2013), 13(5), 445-448.

Zuhairini, Filsafat Pendidikan Islam, (Jakarta: Bumi Aksara, 1995). 